\title{
Developing Self-Revision Oriented Translation Model: Promoting Human's Role as a Post-Editor
}

\author{
Rusdi Noor Rosa ${ }^{1}, Z_{\text {Zl Amri }}^{2}$, Yetti Zainil ${ }^{3}$ \\ \{rusdinoorrosa@fbs.unp.ac.id ${ }^{1}$,amri_zul@yahoo.com², yz2009@ymail.com ${ }^{3}$ \} \\ English Department, Faculty of Languages and Arts, Universitas Negeri padang, Padang, Indonesia ${ }^{1,2,3}$
}

\begin{abstract}
This article aims at developing a translation model highlighting selfrevision as the central of the model. The model is developed based on the research on the problems encountered by student translators in translation process. The study was conducted using a descriptive qualitative method. The data were the translation process and the results of retrospective questionnaires taken from student translators. The data were collected using Translog, Camtasia Studio 8 and retrospective questionnaire. Three students taking the translation subjects in the English Department of Universitas Negeri Padang were taken as the participants. The results of the data analysis showed that the problems encountered by the student translators included terminology (local terms, collocation, and idiomatic expressions), structure of the target language (commonly used in the TL written articles), and cohesiveness (composed of well organized clauses). Based on such research findings, a new model oriented to self-revision was developed.
\end{abstract}

Keywords: Translation model, translation problems, translation process, selfrevision.

\section{Introduction}

Translation is a process of finding meaning equivalence in at least two different languages for which different models have been developed. Unlike product-oriented translation, frequently focusing on errors in translation (e.g. [1], [2]), translation assessment (e.g. [3]-[5]), translation techniques (e.g. [6], [7]), studies in process-oriented translation focus on the actual process taking place in the translation process. Such a number of studies on process-oriented translation are conducted to produce later models of translation process considering the weaknesses or limitations of the early ones based on the analysis of 'what happened' during translation process. The so-called meaning-based translation [8], [9], psycholinguistic model of translation processes [10], factored translation model [11], translation competence model [12], discourse and communication translation model [13], and cognitive model [14] are some instances of the translation process based models. However, most of those models are not developed based on the actual translation problems found in the field. In other words, they are not directed to the actual problems, but are addressed to common problems in translation process. Only does Moghadas and Sharififar's model [14] put emphasis on translation problem-solving, dealing with the cognitive process of finding the equivalent of neologism used in the source text (ST). 
However, the problem highlighted in their model (see Figure 1) is only related with neologisms (newly coined words), one of many other problems encountered in translation process. In addition, the solution to the problem is not specified, relying only on the translator's cognition through their ability in linguistic analysis and drawing inferences. Nevertheless, this model provides reasonable procedures before finalizing the translation draft by providing an interactive cycle - semi-acceptable, not acceptable and acceptable. The target text (TT), therefore, contains only acceptable solutions to the neologisms. Moreover, the model also emphasizes on reading and comprehending the neologisms in the ST, two main activities in the pre-drafting phase, indicating the involvement of human translator in the whole translation process.

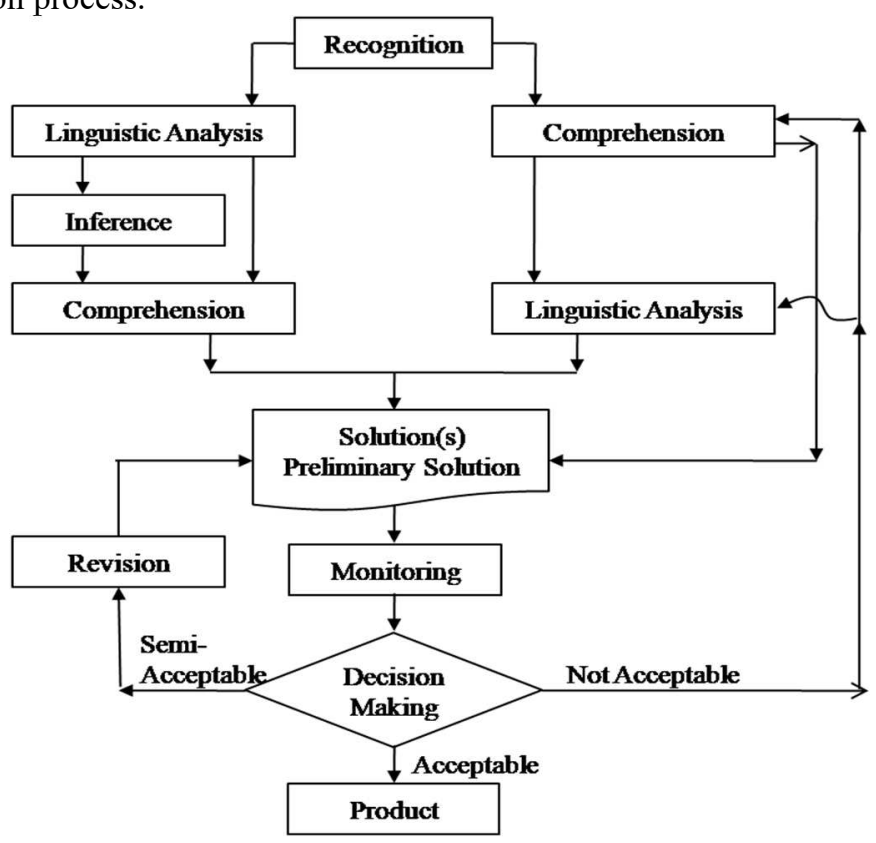

Figure 1 Cognitive model of neologisms translation

Moghadas and Sharififar's model [14] starts with recognizing and comprehending the neologism in the ST during which a translator depends on his/her world knowledge or experiences (cognitive processing) through linguistic analysis as shown in Figure 1.

Recently, through the invention and development of Computer Assisted Translation (CAT) and Machine Assisted Translation (MAT), translation is no longer seen as exclusively a human process [15]. In addition, Rosa et al. [16] argue that professional translators tend to skip pre-drafting and drafting phases as they let machines (CAT or MAT tools) do such activities. In addition, understanding the ST, the ultimate purpose of activities in the predrafting phase, can be achieved while doing revisions during which a translator has an opportunity to read the ST and the TT to get an understanding of both texts.

Based on the rational elaborated in the previous paragraphs, this study aims at finding out the problems faced by student translators in the translation process and developing a translation model corresponding to such problems. 


\section{Method}

This was a qualitative research for the purpose of exploring problems and deeply understanding a central phenomenon development [17]. In this study, the central phenomenon requiring exploration and understanding was the translation process from English into bahasa Indonesia. The data of this research were the process of translation, and the source of data was the English text entitled 'Plantations are a dark chapter in American history-here's why to visit' downloaded from https://www.nationalgeographic.com/travel/intelligenttravel/2016/02/01/the-plantation-every-american-should-visit/. The research participants were three student translators (hereinafter called Student), the students of English Department of Universitas Negeri Padang taking translation subject as their elective course. They were asked to translate the text from English into Bahasa Indonesia. They were not allowed to use any printed resources; only online resources were allowed. The participant selection criteria followed Kourouni's suggestions [18] emphasizing on the participants' homogeneous profile in terms of: (i) being familiar with major web search techniques for translation purposes; (ii) being familiar with the type and style of texts to be translated; (iii) being Indonesian native speaker; (iv) having no professional translation practices in the past; and (v) belonging to the same age group.

Keylogging tool (Translog), screen recording tool (Camtasia Studio 8) and retrospective questionnaire were used as the instruments of data collection. The Translog was used to record keyboard activities while doing the translation task, and Camtasia Studio 8 was used to record the screen activities, including both online and offline activities, during translation process. Meanwhile, the retrospective questionnaire was given to confirm the difficulties encountered during the translation process and the solutions taken by the participants to such difficulties.

The data were analyzed qualitatively through the procedures suggested by Lauffer [19]. Firstly, the data were analyzed to find the problems encountered by the Students, indicated by the pauses taken by the participants while translating the text. The analysis continued to find out their activities while taking pauses in terms of cognitive, metacognitive and socialaffective processing. Then, the results of questionnaire were used for the purpose of data triangulation to confirm the results of keylogging and screen recording analysis. Besides, the results of the questionnaire gave the information of the solution undertaken by the Students to the translation problems they encountered. The results of the data analysis were then used as the basis of developing a new model of translation.

\section{Results and Discussion}

The results of data analysis show that terminology (local terms, collocation, and idiomatic expressions), structure of the target language (commonly used in the TL written articles), and TT cohesiveness (composed of well organized clauses) are the problems faced by the Students in the translation process. The problems of finding the equivalent of local terms are very obvious when none of them translates the ST phrase "Louisiana's historic River Road" accurately. Student A uses "River Road yang cukup bersejarah di Louisiana" as its equivalent, meaning that only the word 'historic' is translated, while others are kept. The screen recording tool recorded no activities when he took pauses in finding its equivalent, indicating his reliance on his previous knowledge. Meanwhile, Student B writes "Jalan Sungai bersejarah di Louisiana" as the equivalent. Although this is better than the equivalent provided by Student 
A, the use of "Jalan Sungai" remains vague as it might mean "traveling along a river", "a name of one of the roads in Lousiana", or "a road around a river". The decision of Student B was caused by the help of online resources. She used Google Translate (GT) to get the literal meaning of the phrase and confirmed the meaning by reading the online article entitled "Explore Louisiana's Historic River Road Plantations - 97.3 The Dawg" (http://973thedawg.com/explore-louisianas-historic-river-road-plantations/). Like Student A, Student C also keeps the phrase "River Road" considering that it is the name of the road located in Louisiana. The difficulty of finding the right equivalent of local terms has also been confirmed by Rosa et al. [16]. The local terms "Federal Writers' Project", "antebellum plantations", "Louisiana's Whitney Plantation", and "west bank of the Mississippi" are other local terms presenting equivalence difficulties to the Students.

In addition to the local terms, idioms or idiomatic expressions also present another difficulty to the Students in translation process. None of the Students successfully found the right equivalent for the idiom "a dark chapter". Two of them (Student B and C) translated it literally, while the other one (Student A) used a discursive creation technique by writing "lembaran kelabu (gray page)" as its equivalent. Although such phrase in bahasa Indonesia indicates sad moment, the use of "black" color, in this context, is preferable. Besides, translating the idiom "mixed bag" is also the problem faced by the Students. Nevertheless, one of the Students successfully found the right equivalent to such idiom, i.e. bermacam-macam. The main factor leading to his ability to find the right equivalent to such idiom is his knowledge of the context where the idiom is located. A number of online resources were visited such as GT (a diverse assortment of things or people), Merriam-Webster dictionary (a miscellaneous collection), Cambridge English Dictionary (a situation involving a variety of things), and Collins English Dictionary (a situation containing some good items, features, or people and some bad ones). Based on the definitions provided in those online resources, he concluded that "mixed bag" is equivalent with "various" or "diverse". Translating idiomatic expressions is difficult [20]for being so culturally different that translators need to have good skill in managing which online resources best help them solve such problem. Similarly, Joodi [21] argues that translating idioms has always been very difficult for foreign language learners.

Writing grammatically accepted clauses in the TL (bahasa Indonesia) is also the problem encountered by the Students. As translation product is a written text, they must be competent in Indonesian written language. The results of the questionnaire show that they do not recognize their weakness in writing Indonesian grammatically accepted clauses; however, the results of keylogging and screen recording analysis reveal such difficulties. For example, Student B had written three drafts before deciding to write "Perkebunan Louisiana Whitney membayar penghormatan kepada pengalaman para budak didaerah Selatan" as the equivalent of the ST clause "Louisiana's Whitney Plantation pays homage to the experiences of slaves across the South". In addition to writing the incorrect structure of TL phrase "Perkebunan Louisiana Whitney", the problem also includes the incorrect use of preposition "di". In the Indonesian structure, the morpheme "di" functions as both prefix and preposition. As a prefix, "di" and its following word (root or base) are written as a single word; but as a preposition, they are written in two separated words. Therefore, the correct structure of the phrase should be "di daerah". Besides, writing three drafts has obviously indicated difficulties in writing TL grammatical clauses, and the final draft does not also show her good competence in constructing an Indonesian correct clause.

The main factor leading to the problems of finding equivalent and writing a good structure is the Students' poor ability in online resources management [22]. Utilizing online 
resources indicates the application of social-affective processing in translation problem solving. Online resources do not only allow one-way communication but also two-way communication. The recognized translator association (Association of Indonesian Translators, known as HPI) facilitates two-way communication for those encountering problems in translation through Facebook media. The possible interaction between human and computer in translation process is also confirmed by O'Brien [23]. Human-computer interaction, adapting Johnson's definition [24], is the study of the interaction between people (translator), computers and translation tasks.

The other problem is the TT cohesiveness. Adopting the SFL theory concerning thematic progression ([25]-[28]) could have been the best solution to produce a well organized TT. It is argued that thematic progression could improve the cohesion of a text [26], [27]. In translation, thematic progression is related to the translator's decision to locate certain clause elements in the theme position considering the flow of the ideas contained in other clauses. Such theme choice enables translators to use their own style of writing corresponding to the prevailing TL structure, which may lead to the TT naturalness, i.e. showing the TT independence over the ST interference. In other words, the theme of the clause in the ST might not be the theme of the clause in the TT.

Based on the problems encountered by the Students elaborated in the previous paragraphs, a model of translation process using an SFL language metafunction theory is developed. This model, like the translation model proposed by Moghadas and Sharififar [14] which emphasizes on translation problem solving and revision, also emphasizes on the important role of revision (self-revision), and it is even the central of the model. In addition, this model emphasizes that translation cannot be divorced from language competence and translators. The translation model proposed in this study is presented in Figure 2.

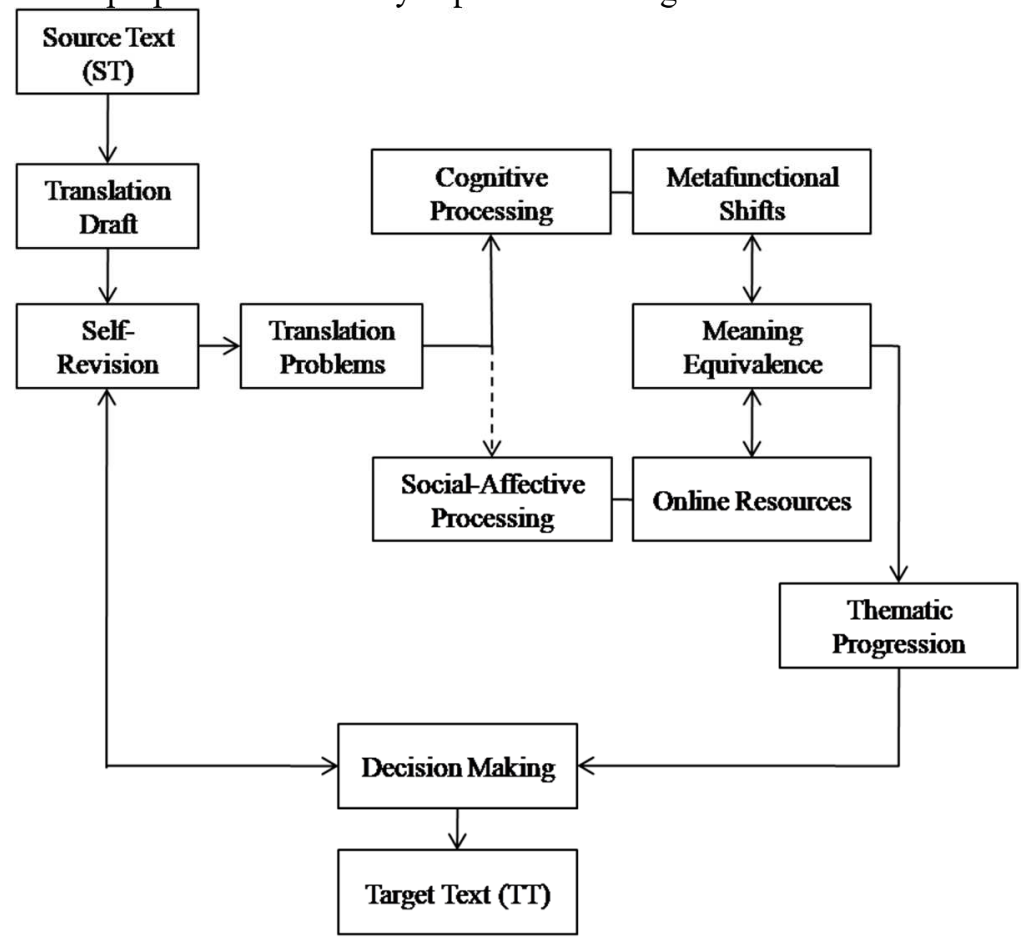

Figure 2 The self-revision oriented translation model 
The model in Figure 2 is particularly designed for translation process from English as the source language (SL) into bahasa Indonesia as the target language (TL). According to this model, the translation process begins by writing the translation draft of the source text (ST). The processes taking place in this stage are pre-drafting and drafting. However, in this model, the pre-drafting and drafting processes are not specified as different translators might use different methods and approaches. With the upcoming issue of the human's role as a posteditor, the two processes are given to a machine translation provided by Internet services. Reading the ST, used to be the activity in pre-drafting, is usually skipped because it is no longer effective as understanding the ST can be gained while doing revision in which translators read both the ST and the translation draft.

Once the translation has been drafted, the next step is to do self-revisions. The term 'selfrevision' must be clearly distinguished from the term 'revision'. The former is done by a reviser who is not the translator, while the latter (called self-revision) is done by the translator himself/herself, which is the concern of this model. In addition self-revision views revision as a process [29], corresponding to the nature of this model as a translation process-based model. Based on this model, a self-revision is the central activity in translation process; therefore, it must be given a priority in time allocation. Even though self-revisions are sometimes done simultaneously while drafting, a good translator should allocate a specific time for selfrevisions because revisions while drafting are usually addressed at group/phrase level or clause level.

In addition to self-revisions at word, group/phrase, and clause level, the self-revision in this model includes a revision at text level. While doing self-revisions, a translator has an opportunity to read and understand the ST to confirm whether the original meaning of the ST has been included in the translation draft. This process results in identifying translation problems encountered. The problems include terminology (local terms, collocation, and idiomatic expressions), structure of the target language (commonly used in the TL written articles), and TT cohesiveness (composed of well organized clauses). Such translation problems could be resolved through cognitive processing and/or social-affective processing (indicated by the use of two-direction arrow). This means that resolving the translation problems must go through cognitive processing, and the heavier the problems are the heavier the load of cognitive processing will be. Meanwhile, a social-affective processing is a supporting processing to reduce the load of the cognitive processing (indicated by the use of dotted line).

In a cognitive processing, translators have to activate their previous knowledge related to the problems encountered. In this model, SFL theory is applied as the basis of cognitive processing, particularly in terms of language metafunctions. Therefore, in a cognitive processing, the decision to shift or not to shift should be based on metafunction point of view. The decision to shift results in metafunctional shifts that include ideational shifts, interpersonal shifts, and textual shifts. Shifts are needed to confirm that the TT sounds natural to the TL readers and is free of the SL interference either in terms of structure and style. However, it should be noted that in doing shifts, translators have to guarantee the meaning equivalence which means that the shifts must not change the original meaning of the ST message.

Meanwhile, social-affective processing, considered as the supporting element in translation process, plays a very important role in this model. The use of social-affective processing is realized in the use of online resources to solve the translation problems mentioned above. Here, translators are expected to have good online resources management, i.e. the ability to find the right online resources for the problems encountered within a short 
period of time. Therefore, using online resources, considered to be much time consumption, can solve the translation problems faster if managed well. As Kourouni [18] reported that more than half of her research participants $(60 \%)$ stated that they had enough time to perform the internet searches they wished to make.

In this model, using online resources can help solve such translation problems as terminology and structure. Online dictionaries and thesaurus provide solutions over terminology problems faced by translators. In addition, various websites provide general guidelines of enhanced Indonesian spelling that would be very helpful in examining the structure of bahasa Indonesia. In addition, online news and articles could serve as references for the acceptability of the TT. The application of SFL language metafunction and the utilization of online resources are intended to obtain the proper meaning equivalence. Discovering the meaning of the ST and re-expressing such meaning in the TL are the main two activities in translation process.

Once the translation draft contains clauses whose meanings have been equivalent to the ST clauses, translators should pay attention to the cohesiveness of the draft as a good TT must be cohesive. As mentioned earlier, cohesiveness is one of the problems found in the translation of the Students. At this stage, thematic progression can be used as the means to evaluate the text cohesiveness. Thematic progression, the progression of theme and rheme elements, allows translators to deviate from the style and structure used in the ST, contributing to the naturalness of the TT. Such deviation results in translation shift, especially theme shift.

The cognitive processing and social-affective processing undergone by translators together with confirming the cohesiveness of the translation draft lead to the next step of translation process, i.e. decision making. Whether the possible solutions to the translation problems are accepted would be the personal right of a translator as the decision maker. To keep a certain ST word in the TT for finding no exact equivalent in the TL, for example, is one of the hard moments experienced by translators requiring their right decisions. Decision making is the last step of revision according to this model. However, indicated by the use of two-direction arrow in Figure 1, it is not the final step because there is a possibility to redo the steps from the initial activity in self-revisions.

Once the decision has been final; in other words, the translators have done all their efforts in self-revisions, the target text (TT) is produced. After the TT is produced, there is no more revision; therefore, the translators have to be careful in finalizing their revisions.

\section{Conclusions}

The model developed in this study is called self-revision oriented translation model which is developed based on the actual problems -terminology, structure and cohesiveness- faced by student translators in the translation process. In addition, this model supports the issue of human translator as a post-editor. Human translators do no longer start translation process by drafting word by word, clause by clause, or paragraph by paragraph, but they let the machine (e.g. Google Translate) do such drafting. Therefore, they will be busy doing revisions at the post-drafting phase.

The translation model developed in this study is not yet completely reliable; therefore, it is suggested to use it in translation process to see how it works. Critics and suggestions are welcomed to make it better. 
Acknowledgments. The writers would like to thank the Research Institute of Universitas Negeri Padang for funding this research.

\section{References}

[1] P. Q. N. Pham, P. Djité, S. J. Campbell, and S. Hale, "Error analysis in vietnamese english translation: pedagogical implications," School of Humanities and Languages. 2005.

[2] J. Mercader-Alarcón and F. Sánchez-Matínez, “Analysis of translation errors and evaluation of pre-editing rules for the translation of English news texts into Spanish with Lucy LT," Tradumàtica Tecnol. la traducció, 2016.

[3] J. House, Translation quality assessment. A model revisited. 1997.

[4] M. Ghourchian, "Speech acts in drama translation," Asian EFl J., vol. 60, no. 2, pp. 70-84, 2012.

[5] G. Medadian and D. N. Mahabadi, "A summative translation quality assessment model for undergraduate student translations: Objectivity versus manageability," Stud. About Lang., 2015.

[6] L. Molina and H. Albir, "Translation techniques revisited: A dynamic and functionalist approach," Meta, XLVII, 2002.

[7] J. Đorđević, "Translation techniques revisited: The applicability of existing solutions in non-literary translation," Facta Univ. Ser. Linguist. Lit., 2017.

[8] D. P. Verity and M. L. Larson, "Meaning-based translation: A guide to cross-language equivalence," Mod. Lang. J., 1986.

[9] Nurlela, R. Sofyan, and Gustianingsih, "Translating Hikayat Deli into bahasa Indonesia and the need of meaning-based translation model," Int. J. English Lang. Transl. Stud., vol. 6, no. 1, pp. 75-80, 2018.

[10] D. Kiraly, Pathways to translation: Pedagogy and process. Kent, Ohio: Kent State University Press, 1995.

[11] P. Koehn and H. Hoang, "Factored translation models," in EMNLP-CoNLL 2007 Proceedings of the 2007 Joint Conference on Empirical Methods in Natural Language Processing and Computational Natural Language Learning, 2007.

[12] S. Göpferich, "Towards a model of translation competence and its acquisition: The longitudinal study TransComp," Behind Mind Methods, Model. Results Transl. Process Res., 2009.

[13] T. Volkova, "Translation model, translation analysis, translation strategy: An integrated methodology," Procedia - Soc. Behav. Sci., 2014.

[14] Seyed Mohammad Moghadas and M. Sharififar, "A model for cognitive process of neologisms translation," Int. English Lang. Transl. Stud., vol. 2, no. 1, pp. 4-19, 2014.

[15] M. Manfredi, Translating text and context: translation studies and systemic functional linguistics, vol. 1. Bologna: Centro di Studi Linguistico-Culturali (CeSLiC), 2008.

[16] R. N. Rosa, T. S. Sinar, Z. Ibrahim-Bell, and E. Setia, "Pauses by student and professional translators in translation process," Int. J. Comp. Lit. Transl. Stud., vol. 6, no. 1, pp. 18-28, Jan. 2018.

[17] J. W. Creswell, Educational research: Planning, conducting, and evaluating quantitative and qualitative research. 2012.

[18] K. Kourouni, "Translating under time constraints in an undergraduate translating under time constraints in an undergraduate context: A study of students 'products, processes and learning styles," Universitat Rovira I Virgili, 2012.

[19] S. Lauffer, "The translation process: An analysis of observational methodology.," 
Cad. Tradução, 2002.

[20] A. Shojaei, "Translation of idioms and fixed expressions: Strategies and difficulties," Theory Pract. Lang. Stud., 2012.

[21] A. M. H. Joodi, "A study of the problems of learning and translating idioms," J. Coll. Educ. Women, vol. 23, no. 4, pp. 1205-1247, 2012.

[22] R. Sofyan and B. Tarigan, "Online resources management in self-corrections and translation quality,” Int. J. Sci. Basic Appl. Res., vol. 35, no. 2, pp. 212-224, 2017.

[23] S. O’Brien, "Translation as human-computer interaction," Transl. SpacesTranslation Spaces A Multidiscip. multimedia, Multiling. J. Transl., 2012.

[24] P. Johnson, Human-computer interaction: psychology, task analysis and software engineering. Maidenhead: McGraw-Hill, 1992.

[25] S. Eggins, An Introduction to Halliday's Systemic Functional Linguistics. 2004.

[26] L. Wang, "Theme and rheme in the thematic organization of text: Implications for teaching academic writing," Asian EFL J., 2007.

[27] R. N. Rosa, "Thematic progression as a means to keep cohesion in exposition text," $J$. Bhs. dan Seni, vol. 8, no. 2, p. 94, 2007.

[28] W. Gunawan and F. Aziza, "Theme and thematic progression of undergraduate thesis: Investigating meaning making in academic writing," Indones. J. Appl. Linguist., 2017.

[29] I. Robert, "Translation revision procedures: An explorative study," in Translation and Its others: selected papers of the CETRA Seminar in translation Studies 2007. With an introduction by Miriam Shlesinger, 2008. 